Progress in Soil Science

Wenceslau Geraldes Teixeira

Marcos Bacis Ceddia

Marta Vasconcelos Ottoni

Guilheme Kangussu Donnagema

Editors

Application of

Soil Physics in

Environmental

Analyses

Measuring, Modelling and Data Integration

Dpringer 


\section{Progress in Soil Science}

\section{Series Editors:}

Alfred E. Hartemink, Department of Soil Science, FD Hole Soils Lab, University of Wisconsin-Madison, USA

Alex B. McBratney, Faculty of Agriculture, Food \& Natural Resources,

The University of Sydney, Australia

\section{Aims and Scope}

Progress in Soil Science series aims to publish books that contain novel approaches in soil science in its broadest sense - books should focus on true progress in a particular area of the soil science discipline. The scope of the series is to publish books that enhance the understanding of the functioning and diversity of soils in all parts of the globe. The series includes multidisciplinary approaches to soil studies and welcomes contributions of all soil science subdisciplines such as: soil genesis, geography and classification, soil chemistry, soil physics, soil biology, soil mineralogy, soil fertility and plant nutrition, soil and water conservation, pedometrics, digital soil mapping, proximal soil sensing, soils and land use change, global soil change, natural resources and the environment.

For further volumes:

http://www.springer.com/series/8746 
Wenceslau Geraldes Teixeira

Marcos Bacis Ceddia

Marta Vasconcelos Ottoni

Guilheme Kangussu Donnagema

Editors

\section{Application of Soil Physics in Environmental Analyses}

Measuring, Modelling and Data Integration

\section{Springer}


Editors

Wenceslau Geraldes Teixeira

Guilheme Kangussu Donnagema

Soil Physics

Embrapa Soils

Rio de Janeiro, RJ, Brazil

Marta Vasconcelos Ottoni

Department of Hydrology

Companhia de Pesquisa de

Recursos Minerais (CPRM)

Geological Survey of Brazil

Rio de Janeiro, RJ, Brazil
Marcos Bacis Ceddia

Soils Department

Rural Federal University of Rio de Janeiro

Seropédica, RJ, Brazil
Forewor

The singular it recognized. T Nations Gener Various discip tionally provid and character biological pro both affect an as well as the without soil p?

It is the tim mechanisms c formation pros knowledge ap tions and man warming pola known about of means to mechanisms carbon seque controls of the

New prosp wireless soil n and hydrogeo able. Clearly, content sensit providing unic tial challenge: The developm sents an excit

Printed on acid-free paper

Springer is part of Springer Science+Business Media (www.springer.com) 


\title{
Chapter 4 \\ Spatial Relationships Between Soil Water \\ Content and Hydraulic Conductivity in a Highly Structured Clay Soils
}

\author{
Sidney Rosa Vieira, Célia Regina Grego, George Clarke Topp,
} and Willian Daniel Reynolds

\begin{abstract}
The water, element essential for life, is present as a large reservoir in the soil. Soil water content varies in space as a consequence of the variability. of other related properties and its study is necessary. to know how this variation occurs in space and time. The objective of this study was to assess the spatial and temporal variability of soil water content and its relationships with hydraulic conductivity. Soil water content was measured with a TDR equipment and the hydraulic conductivity was measured with a constant head well permeameter at 15 and $50 \mathrm{em}$ depth, in a nearly flat 1,2 ha field at the Central Experimental Farm of the Agriculture Canada, Ottawa. The soil is classified as a Rideau soil series, is primarily clay to silty clay texture. Sampling was made on a $10 \mathrm{~m}$ spacing square grid with 164 sampling points. Soil water content was measured on 33 dates during the frost free months in 1987, 1988 and 1989. The rate of change in soil water content was calculated for the periods, which did not have any rain. The spatial variability was analyzed examining the descriptive statistical parameters, the parameters of the models fitted to individual semivariograms as a function of time and the maps obtained by kriging interpolation. It was concluded that soil structure played a very important role on the spatial distribution of hydraulic conductivity and water content.. Temporal stability of water in the soil is quite different during the year probably because of the hydraulic conductivity. role.. Parabolic trend removal
\end{abstract}

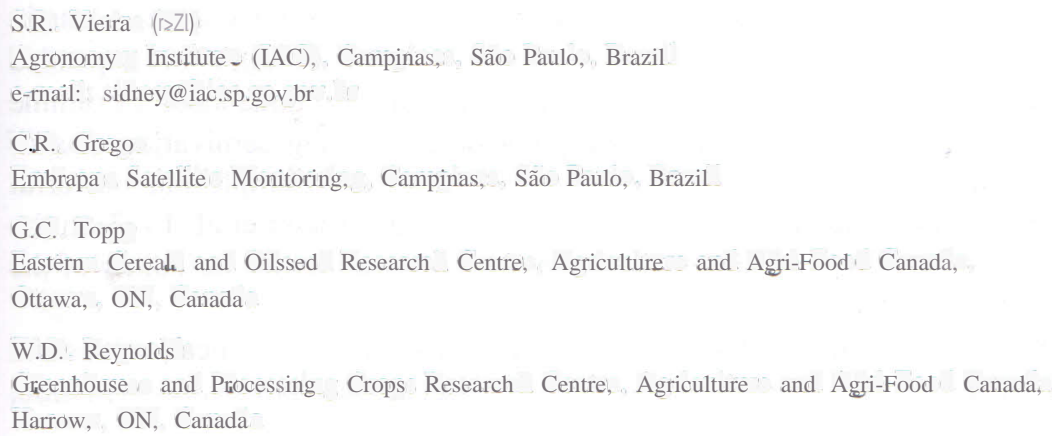


worked well ali through the year probably because of the topography. The behavior of spatial variability the rate of change in water of soil did not repeat in different times of the year' studied.

Keywords TDR. Temporal stability - Semivariogram • Geostatistics

\subsection{Introduction}

The water, element essential for life, is present as a large reservoir ${ }_{1}$ in the soil. Their distribution in space is variable due to fluctuations of other related properties, so knowledge of this variation in space and time becomes important in studies of soil physical properties. Soil water changes over landscape have been identified in several studies. Vauchaud et aI. (1985) found temporal stability of frequency distribution of water in the soil, Kachanoski and De Jong (1988) studied the temporal persistence of spatial pattems of soil water storage, Vieira et ai (1997) reported on the scaling of spatial vabiability over time and Gonçalves et aI (1999) observed a temporal stability of soil water content stored in an irrigated area. During the last few decades geoestatistical methods have been intensively used for descriptions of spatial variability in depth (Nielsen et aI. 1983; Vieira et aI. 1983; Vieira 2000; Grego and Vieira 2005; Vieira et ai 2008). Most of the authors reported that geoestatistics is useful for evaluate the spatial dependence, use this spatial dependence to interpolate values for the places where they have not been measured, and to provide information to construct maps and design sampling strategies as a function of the spatial variability. The difference of statistics and geostatistics is that classical statistics require normality and spatial independence of the dates while geostatistics requires correlation and spatjal dependence.

Variability in time, and in particular, with repeating pattems is being a challenge to soil research. Adequate information about soil properties showing spatial distribution stable in time could contsibute to significantly reduce the number of measurements (Vauchaud et aI. 1985; Kachanoski and De Jong 1988). Soil water content analyzed in consecutive sampling dates have been reported of having temporal stability (Vauchaud et al. 1985; Gonçalves et al. 1999). Vauchaud et al. (1985) addressed the occurrence of temporal stability of the spatial distribution of soil water content and concluded that the places where higher water content occur in one moment may remain that way at other moments. Vieira et al. (1991) expanded this concept and considered the scaling of semivariograms to simultaneously examine the spatial variability in consecutive sampling dates. Scaling semivariograms of several variables measured over the same field provides a simple but powerful integration method (Vieira et al. 1988; Vieina et al, 1991; Vieina et al. 1997) in the sense that the more the semivariograms scale the more similar the variability of the corresponding variables are.

Therefore, if semivariograms scale, it indicates that not only the mean values and dispersion coefficients occur at the same locations but all variability repeats in time although the absolute of the models fitted samplings may be of Thus, in order to ar important calculate a semivariogram mod different dates and $n$

The objective of

- To describe the sf distribution for so

- To use geostatisti i hydraulic conduct

- To analyze the ter and its relations

\subsection{Methodolo}

\subsubsection{Study Arie}

The study was deve with clay loam to Agriculture Canada, and sixty four TDRI water content were it obtained on the same in-place at the same and kept there for 3 with the TDR metho

AlI water contem time period. The triar $110 \mathrm{~m}$ in the $\mathrm{x}$-directi a $10 \times 10 \mathrm{~m}$ grid with shown in Fig. 4.1.

The study period. during the ground su September 11, 14, r with different TDR 13 and 30, June 06. September $02,08,1$ were April 14, 18, 21 $\mathrm{mm}$, during the study 
soil. Their perties, so lies of soil entified in frequency tudied the al (1997) t al (1999) ated area ively used 33; Vieira Iost of the dence, use re not been sampling tistics and endence of I challenge al distribuf measureter content g temporal al. (1985) ion of soil nt occur in ) expanded Iy examine iograms of it powerful 997) in the pility of the

values and ats in time, although the absolute values may be different.. Besides, the analysis of the parameters of the models fitted to the semivariograms as a function of the time of successive samplings may be of help in assessing the temporal stability of the spatial variability. Thus, in order to analyze temporal and spatial variability of water content it is important calculate and compare scaled semivariograms for different dates, compare semivariogram model parameters and construct and compare contour maps for different dates and variables.

The objective of this chapter was:

- To describe the spatial variability as well as the temporal stability of the spatial distribution for soil water content.

- To use geostatistics to evaluate the spatial variability of soil water content and of hydraulic conductivity.

- To analyze the temporal stability of the spatial dependence of soil water content and its relations with the soil hydraulic conductivity.

\subsection{Methodology}

\subsubsection{Study Area and Soil Sampling}

The study was developed in a Rideau clay loam soil (Gleyed Melanic Brunisol) with clay loam to clay surface texture, in the Central Experimental Farm of Agriculture Canada, Ottawa, with grasses vegetation maintained low. One hundred and sixty four TDR (time domain. refiectometry) rods for measuring volumetric water content were installed. Therefore, soil water content measurements could be obtained on the same points as many times as wanted since the IDR rods remained in-place at the same points in the field. The TDR rods were installed at $45^{\circ}$ angle and kept there for 3 years. All the soil water content contents. measured were done with the TDR method according to Topp and Davis (1985).

All water content measurements over the field were collected within a two-hour time period. The triangular field, kept vegetated with natural pasture grass, measured $110 \mathrm{~m}$ in the $\mathrm{x}$-direction (base) and $220 \mathrm{~m}$ in the $\mathrm{y}$-direction (height), was divided into a $10 \times 10 \mathrm{~m}$ grid with 164 points. The grid and topographic map of the study area are shown in Fig. 4.1.

The study period extended from early September of 1987 until early May 1989 during the ground surface frost-free months. The dates of samplings in 1987 were September 11,14,17,21,24, and October 29 with two samplings on the same day with different TDR instruments. There were 19 samplings dates in 1988: May 06, 13 and 30, June 06, 13, 21 and 27, July 04, 15, 22 and 28, August 11, 18 and 25, September 02, 08, 15, 22 and 29, and October 06. The dates of samplings in 1989 were April 14, 18,21,25 and 28 and May 01. Figure 4.2 shows the precipitation in $\mathrm{mm}$, during the study período 

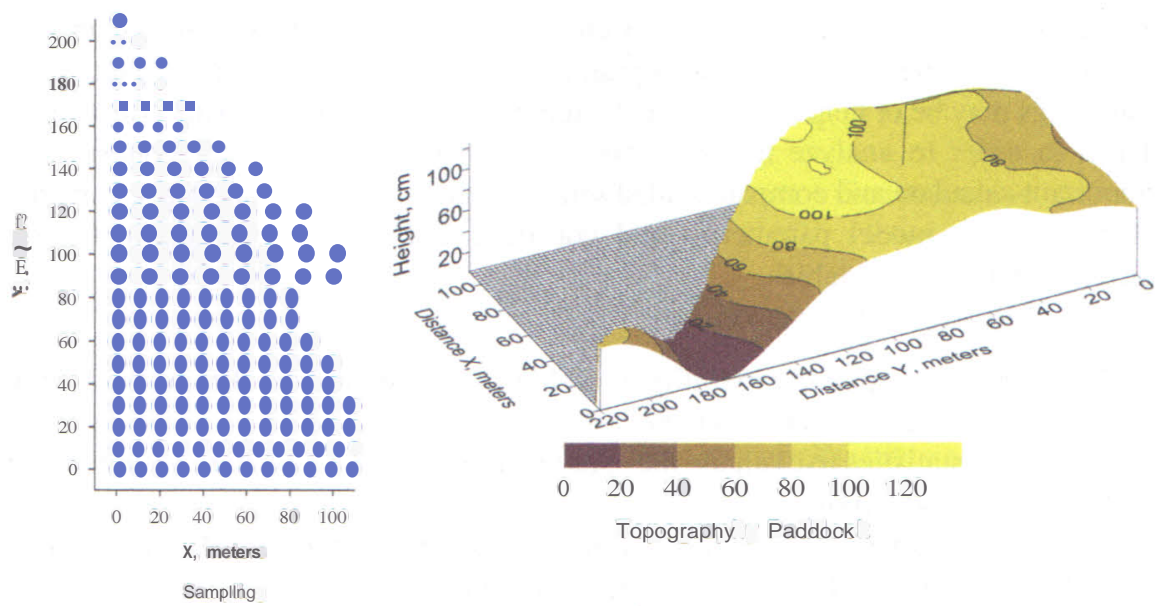

Fig. 4.1 Sampling scheme and topography of the area

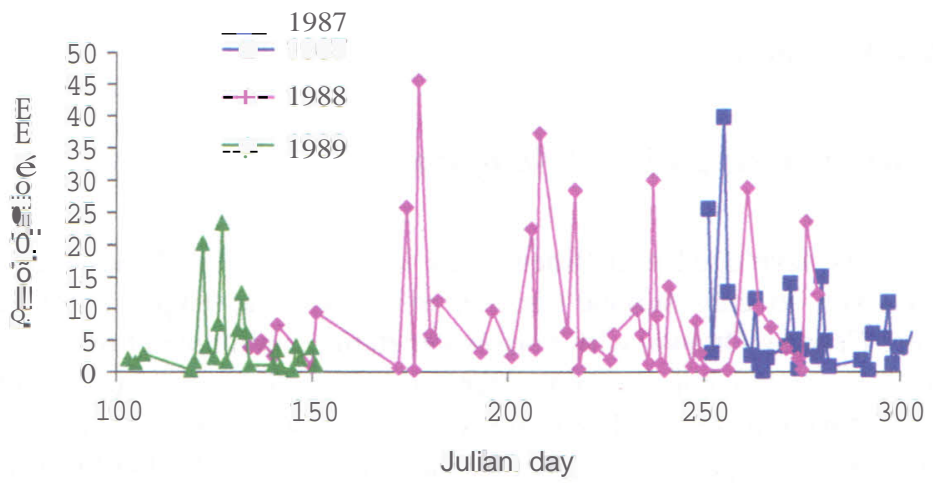

Fig. 4.2 Rainfall as a function of time during the years 1987 until 1989

The sampling dates were converted to Julian days in order to make the parameters plot a function of time during the year:

Figure 4.2 shows a distribution of rainfall during the entire research period for the three years. Except for a few peaks of very high rainfall most of them are somewhere around 5 and $10 \mathrm{~mm}$. Therefore, except for some days right after the peaks of rainfall, it is expected that the major contribution for soil water content is the snow melt.

The field saturated hydraulic conductivity, $\mathrm{K}_{\mathrm{fs}}$, was measured in each one of the locations shown in Fig. 4.1 using the constant head well permeameter (Reynolds and Elrick 1986) and calculated using the one head approach as recommended by Reynolds et al. (1992). At the time the hydraulic conductivity were measured,. TDR readings were made in each one of the 164 sampling points in order to have the initial soil water content.

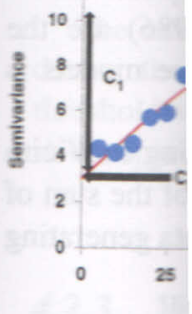

Fig. 4.3 (a) a variance) and 0

4.2.2 Spa

In order to b requirements i a a well-defiped hypothesis, or

Where a ra $\mathrm{E}\{\mathrm{Z}(\mathrm{x})\}$ existi In addition $Z(X j)$ when is variance, and

The functio

where $\mathrm{N}(\mathrm{h})$ is $\mathrm{t}$ a vector $h$ (dist

The main ch Experime nta must meet the (1986). Among parameters that 
a

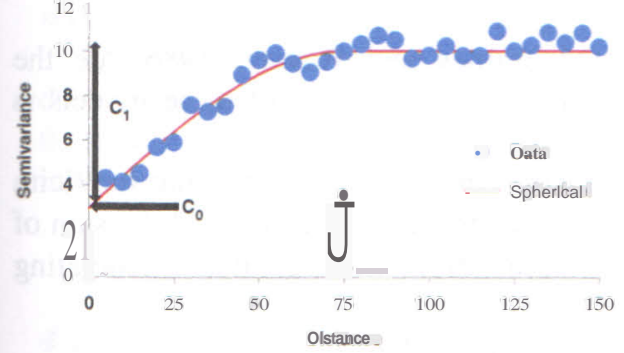

b

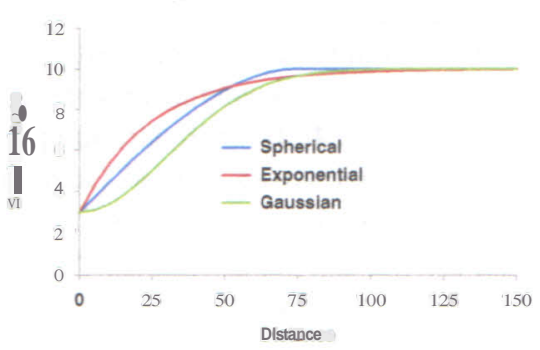

Fig. 4.3 (a) Characteristics of a typical semivariogram with Co (nugget effect), C, (structural variance) and $a$ (range); (b) Mos! commonly used models: spherical, exponential and Gaussianı

\subsubsection{Spatial Variability. Theory}

In order to be able to evaluate the spatiad variability with geostatistics the basic requiliements, are: Cartesian coordinates, intrinsic hypothesis, semivariogram showing a well-detined sill and similarity hetween neighbors. The equations that represent bypothesis for geostatistics are:

$$
E\left\{Z\left(x_{i}\right)\right\}=m
$$

Where a random function $\mathrm{Z}(\mathrm{Xj})$ is stationary' of order two if the expected value, $\mathrm{E}\{\mathrm{Z}(\mathrm{x})\}$ exists and does not depend on the position $\mathrm{x}$.

In addition to the condition in Eq. 4.1, the Eq. 4.2 represent a random function $\mathrm{Z}(\mathrm{xJ}$ when is a intrinsia hypothesis. The inerement $[\mathrm{Z}(\mathrm{Xj})-\mathrm{Z}(\mathrm{Xj}+\mathrm{h})]$ has a finite variance, and does not depend on xi for all vectors $\mathrm{h}$.

$$
\operatorname{VAR}\left[Z\left(x_{i}\right)-Z\left(x_{i}+h\right)\right]=E\left[Z\left(x_{i}\right)-Z\left(x_{i}+h\right)\right]^{\prime 2}
$$

The function $y(h)$ is the semivariogram (Matheron 1963) estimated by

$$
\gamma^{*}(h)=\frac{1}{2 N(h)} \sum_{i=1}^{N(h)}\left[Z\left(x_{i}\right)-Z\left(x_{i}+h\right)\right]^{2}
$$

where $N(h)$ is the number of pairs of measured values $\mathrm{Z}(\mathrm{Xj}), \mathrm{Z}(\mathrm{Xj}+\mathrm{h})$, separated by a vector $\mathrm{h}$ (distance).

The main characteristies of a semivariogram are shown in Fig. 4.3a.

Experimental semivariograms need to be fitted to some mathematical model which must meet the criteria of conditional positive definiteness MaeBratney and Webster (1986). Amongst all the variety of models which satisfy that condition, the fitting 5.muneters that deserihe them are: the nugget effect $\mathrm{Co}$, the sill $\left(\mathrm{Co}_{0}+\mathrm{C} 1\right),(\mathrm{C} 1$ is the 
structured variance coefficient to be defined later), and the range of spatial dependence $a$.

The models most frequently used (McBratney and Webster 1986) are the spherical, the exponential and the gaussian models. A graph of these models is shown in Fig. 4.3b for illustration purposes.

When data shows a trend (semivariogram without a sill), according to Vieira et ai (2010b), an altemative is fit a trend surface using minimization of the sum of squares of the deviations and subtract this surface from the original data generating a residual variable.

For instance, the equation for a parabolic trend surface is:

$$
\text { Zest }(\mathrm{x}, \mathrm{y})=\mathrm{AO}+\mathrm{AIX}+\mathrm{A} 2 \mathrm{Y}+\mathrm{A} 3 \mathrm{X} 2+\mathrm{A} 4 \mathrm{XY}+\mathrm{A} 5 \mathrm{Y} 2
$$

Where $\operatorname{Zest}(\mathrm{x}, \mathrm{y})$ is a estimate value for parabolic trend surface to measured values $(\mathrm{AO}, \ldots$, , ASY $)$

Thus, the residuais, $\mathrm{Zres}(\mathrm{x}, \mathrm{y})$, can be calculated

$$
\operatorname{Zres}(x, y)=Z(x, y)-\operatorname{Zest}(x, y)
$$

With the objective of comparing the variability of different samplings, Vieira et al. (1997) proposed a scaling technique for the sernivariogram expressed by:

$$
\text { ysch }=\text { yLhaL, } \mathrm{L}^{-}=1,2, \ldots, \mathrm{m}
$$

Where $\mathrm{a} i$ is the scaling factor for semivariance (y) and $\mathrm{m}$ is the number of measured variables.

The scale factor a, is a constant that can take the value of the calculated variance, the sill (the highest value of the semivariance) or the square of the mean values. The scaling concept proposed by Vieira et al. (1997) may be helpful in the analysis of the temporal stability of the spatial variability of soil water content corresponding to different sampling dates for the same location.. Withinı each data. set (year of sampling) the scaled semivariograms for all sampling dates can be plotted together in order to mak.e comparisons and verify, if and when the spatial variability loses temporal stability. When data of several dates coalesce into a unified semivariogram structure, it is possible to take advantage of variables having the same spatial structure and, hence, reduce the number of semivariograms needed to analyze and draw interpretations regarding their spatjal variability.

Two facts are very important about the above theoretical concepts: (i) The semivariogram $\mathrm{y}(\mathrm{h})$ is assumed to be isotropic, i.e., either there is no significant anisotropy or there is a transformation to remove the anisotropy before scaling is applied; (ii) $y(\mathrm{~h})$ can take the value of the calculated variance $\operatorname{Var}(\mathrm{z})$ no matter whether it represents the true variance or not, since the scaling factor is simply a number chosen to mak.e the semivariograms coalesce into a single curve. The reason why scaled semivariograms may provide an adequate way to analyze temporal evolution of the spatial variability is that it will be noticeable when the spatial variability pattern changes, and thus the possible cause can be examined.

Therefore,

semivariog

The ex during the threshold $y$ in the spati

4.2 .3

The rate of difference interval (da

The rate period whe caused stric satisfy, the available $\mathrm{fc}$ fièld under to reftect ih prirnaril $\}$ o spatial vari:

\subsection{Res}

Thedes crip and soil wat conductivity

Table 4.1 D measured at 1

\begin{tabular}{l}
\hline Variable \\
\hline Hydráulie :
\end{tabular}

$15 \mathrm{em}$ (10!

Soil water col

Hydraulie cJ

$50 \mathrm{em}$ (10!

Soil water col 


\begin{tabular}{lll} 
& RMSE & Dist \\
\hline 58 & 1.65 & 61 \\
& & \\
18 & 2.41 & 61 \\
51 & 1.12 & 51 \\
57 & 4.67 & 51 \\
\hline
\end{tabular}

the region of same region for hydraulic on why their is that they for hydraulic Imost exactly ntent is high. nivariograms st equally or ent shown in time. Similar mívariograms al variability. 11 me nuggets arical and one inot repeat in for the three olved in these obably reflect of April 1989 ates for 1988 non and rather gree with end ure but rather D.S) showed a d at different le autumn rain he soil and the ibution owing a

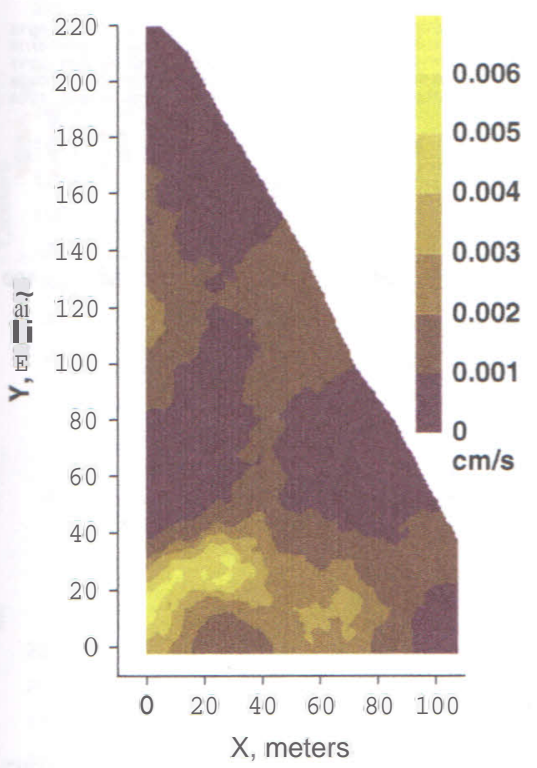

Hydraulie eonduetivity.' (15em)

$\mathrm{C}$

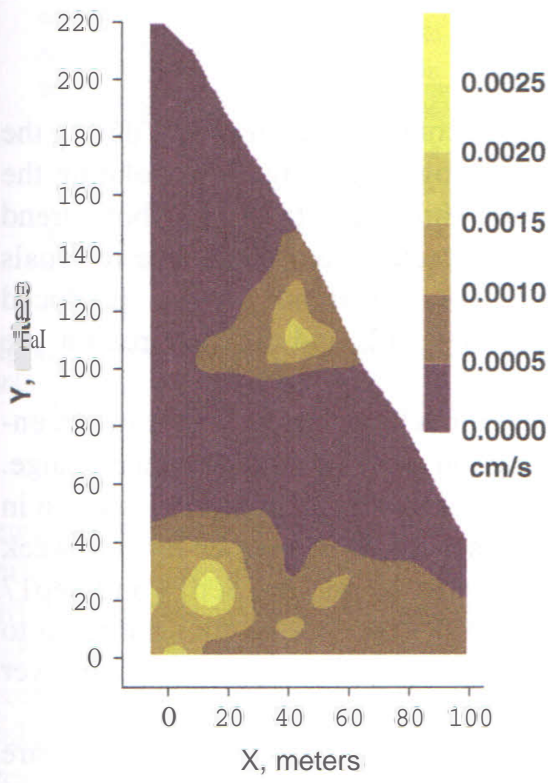

Hydraulie eonduetivity (SOem) b

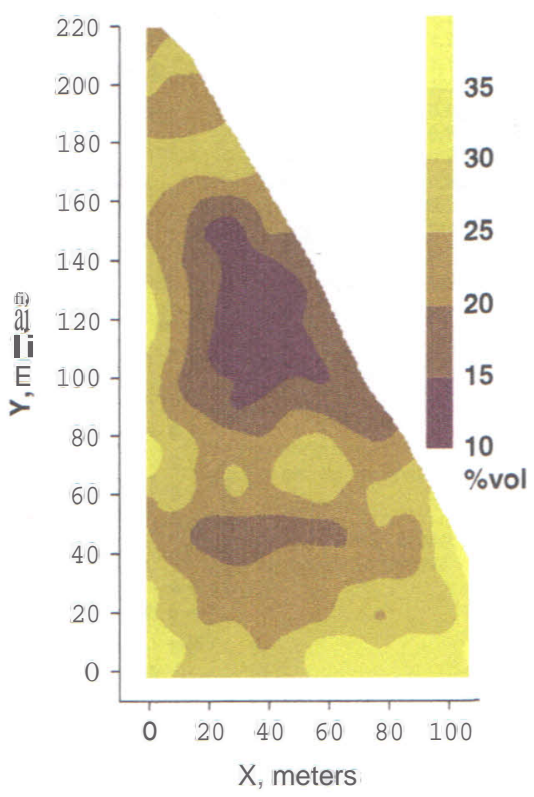

Soi! moisture (15 em)

d

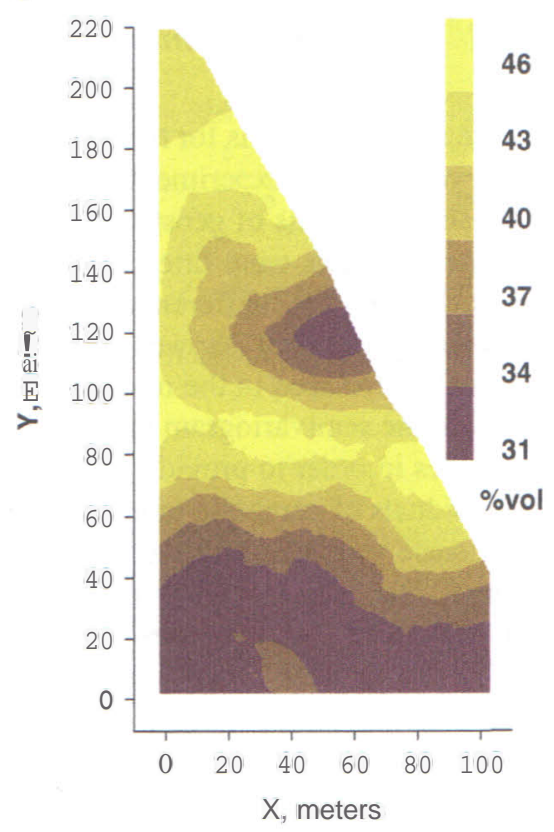

Soi! moisture (50 em)

Fig. 4.5 Maps for hydraulic conductivity (a and b) and soil water content (c and d) at 15 and 50 em depth 
Therefore, scaling is used in this paper only for the comparison between semivariograms for different samplings on the same field,

The examination of the spatial variability for soil water content as the time during the year progresses may reveal information about some water content threshold value at which the soiI hydraulic conductivity begins to cause changes in the spatial variability patterns.

\subsubsection{Water Content Change Over Successive Sampling Dates}

The rate of change of water content over time, ... $\left(8_{\mathrm{i}}, 8_{\mathrm{j}}\right)$ can be expressed as the difference in water content (\% vol.) measured at times $\mathrm{i}$ and $\mathrm{j}$ divided by the time interval (day).

$$
\text { L) } 8 \mathrm{i}, 8 \mathrm{~J}=(\mathrm{Si}-8 \mathrm{j})(\mathrm{ti}-\mathrm{tj})
$$

The rate of change in water content over time, ... $1\left(8 ; 8_{\mathrm{j}}\right)$ was, calculated for the period when there was no rain. Therefore, all the change in water content was caused strictly by water Ioss to the atmosphere. When the soil has enough water to satisfy, the atmospheric demand without restrictions, assuming that the energy available for the evaporation process is not variable in space at the scale of the field under study $(110 \times 220 \mathrm{~m})$, then the variability of the evaporation rate is likely to reflect the soil surface conditions. Besides, because the soil cover constituted primarily of pasture grasses and it was maintained at low height, then not much spatial variability due to vegetation evaporation is expected for this field.

\subsection{Result and Discussion}

The descriptive statistical moments for hydraulic conductivity at 15 and $50 \mathrm{em}$ depths and soil water content measured in 164 points are shown in Table 4.1. The hydraulic conductivity for the two depths showed very high coefficients of skewness and

Table 4.1 Descriptive statistical moments for hydraulic conductivity and soil water content measured at 15 and 50 em depth

\begin{tabular}{lcccccccc}
\hline Variable & Num & Mean & Variance & CV & Min & Max & Skew & Kurt \\
\hline $\begin{array}{l}\text { Hydraulic Conductivity - } \\
\quad 164\end{array}$ & -677 & 291 & $-2,520$ & $-1,135$ & -285 & 009 & -042 \\
$\quad 15$ em (logs) & & & & & & & \\
Soil water content - 15 em & 164 & 2,372 & 3,520 & 2,502 & 1, D70 & 3,640 & -012 & -065 \\
Hydraulic Conductivity - & 164 & -826 & 270 & $-1,991$ & $-1,340$ & -495 & -079 & 016 \\
$\quad 50$ em (logs) & & & & & & & & \\
Soil water content - 50 em & 164 & 3,951 & 5,174 & 1,821 & 1,690 & 5,360 & -033 & -038 \\
\hline
\end{tabular}


Table 4.2 Semivariogram modei parameters for hydraulic conductivity and soil water content measured at 15 and 50 em depth

\begin{tabular}{llrrrrr}
\hline Variable & Model & \multicolumn{1}{c}{ Co } & \multicolumn{1}{c}{ C $_{1}$} & \multicolumn{1}{c}{ a } & \multicolumn{1}{l}{ RMSE } \\
\hline Hydraulic Conductivity $15 \mathrm{em}$ (logs) & Exponential & 228 & 087 & 7,211 & 045 & 0.005 \\
Soil water content 15 em & Spherical & 000 & 2,908 & 7,000 & 080 & 0.139 \\
Hydraulic Conductivity. 50 em (logs) & Spherical & 052 & 203 & 7,000 & 084 & 0.008 \\
Soil water content 50 em & Gaussian & 1,670 & 2,997 & 7,000 & 094 & 0.080 \\
\hline
\end{tabular}

kurtosis. For that reason it was decided to work on the logs rather than the original values. This transfonnation, although it is always better not to need it, it does make the coefficients, of skewness and kurtosis to approach $\mathrm{O}$ (zero). In this condition the data has a frequency distribution close to the normal and it makes the analysis easier according to Vieira (2000).

It can be seen in Table 4.1 that mean hydraulic conductivity is much higher at $15 \mathrm{em}$ than at $50 \mathrm{em}$ depth which is caused by the strong blocky structure at depths near the surface and massive structure at deeper depths. On the other hand the moisture content is much higher at $50 \mathrm{em}$ than at $15 \mathrm{em}$ depth. The coefficients of variation are withim the nonnal range expected for physical soil data of this type. Similar results have been reported by Vieira et al. (1988). One aspect of Table 4,1 which is initially difficult to explaim is the large range in water content (approximately $25 \%$ for $15 \mathrm{em}$ depth and $36 \%$ for $50 \mathrm{em}$ depth). It should be considered that after the snow melt redistribution of water not very much change should be expected for moisture content at $50 \mathrm{em}$ depth this without a crop growing cultivated in this area.

The hydraulic conductivity and soil water content at 15 and $50 \mathrm{em}$ depth showed enough spatial dependence to influence on the interpolation of values at any spacing finer than that they were measured $(10 \mathrm{~m})$ without bias and with minimum variance, as the parameters for the models fitted to the semivariogram (Table 4.2) indicate. The range of spatial dependence was $70.0 \mathrm{~m}$ or more for allof them. The spatial dependence for the hydraulic conductivíty for the $15 \mathrm{em}$ depth was somewhat weak due to the randomness of the macro pores at the surface layer which causes a lot variable in the water flow.

The Fig. 4.4a, b show the scaled semivariograms for hydraulic conductivity and soil water content, respectively, at 15 and $50 \mathrm{em}$ depth. The Rideau soil at this site has a very strong blocky structure at the first $25 \mathrm{em}$. On the other hand, at $50 \mathrm{em}$ depth this soil has a very massive structure or no structure at all. Therefore, at $15 \mathrm{em}$ depth the water moves much faster in between the structure blocks while the soil water content is mostly retained inside the blocks. That is the main reason why the scaled semivariograms for $15 \mathrm{em}$ depth are so different because they represent different soil physical processes. On the other hand, at 50 em depth the water moves faster where there is more water and for that reason, the spatial variability of soil water content is so similar to that ofthe hydraulic conductivity. According to Vieira et al. (1997) the soil physical process is the main reason why scaled semivariograms are so alike. 

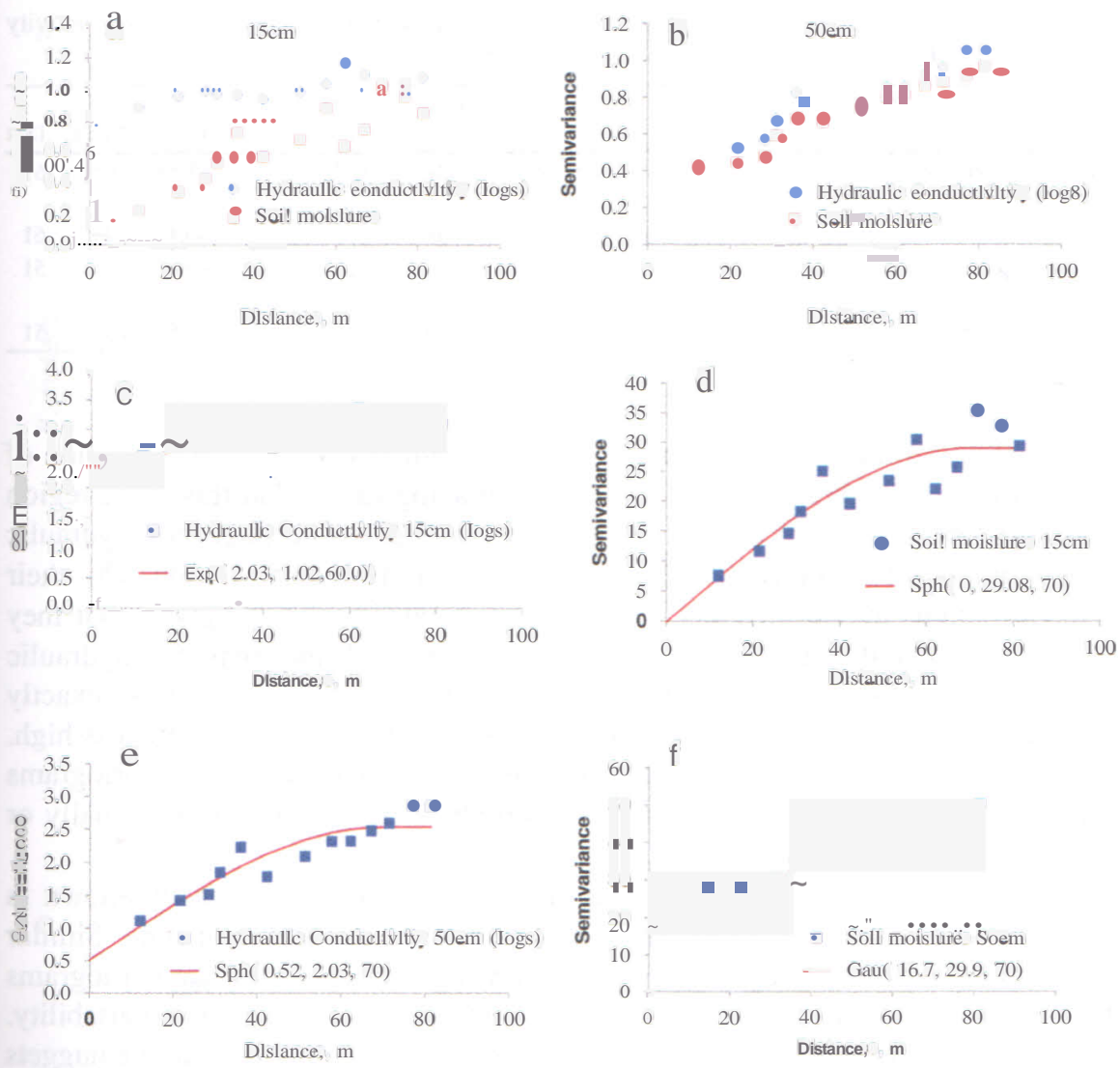

Fíg, 4.4 Semivariograms for hydraulie eonduetivity and water eontent:; (a) sealed semivariogram :or hydraulie eonduetivity and water eontent at $15 \mathrm{em}$ depth: (b) sealed semivariogram for laydraulic eonduetivity and water eontent at $50 \mathrm{em}$ depth; (c) semivariogram for hydrauJie conductivity (Iogs) at $15 \mathrm{em}$ depth; (d) semivariogram for water eontent at 15 em depth; (e) semivasiogram for hydraulie eonduetivity (logs) at 50 em depth; (f) semivariogram for water content at 50 em depth

Figure 4,4c-f., show that the models chosen to fit the semivariograms worked very wvell for all of them as the models follow the experimental. semivariograms with strong spatial dependence as it is also indicated by the $r^{2}$ values shown in Table 4.2.

The spatial dependence expressed by the semivariograms parameters shown in Table 4.2 are validated by the jack knifing procedure whose parameters are shown in Table 4.3. According to Vieira et aI, (2010a) the main parameters in Table 4.3 are the mean error and the variance ofthe errors, which should be, respectively, O(zero) and 1 (one). Thus it can be concluded that all 4 semivariograms are validated as their parameters approach the ideal values.

The maps for hydraulic conductivity and soil water content measured at the time Zae hydraulic conductivities were measured are shown in Fig. 4.5. The region in the 
Table 4.3 Jaek knifing results for the semivariogram model parameters for hydraulie eonduetivity and soil water eontent measured at 15 and 50 em depth

\begin{tabular}{|c|c|c|c|c|c|c|c|c|c|}
\hline Variable & Neighbors & A & $\mathrm{b}$ & $\therefore-$ & $\begin{array}{l}\text { Mean } \\
\text { error }\end{array}$ & $\begin{array}{l}\text { Varianee of } \\
\text { errors }\end{array}$ & UK & RMSE & Dist \\
\hline $\begin{array}{l}\text { Hydraulie Conduetivity } \\
15 \mathrm{em} \text { (logs) }\end{array}$ & 16 & -6.17 & 0.09 & 0.25 & 0.00 & 0.97 & -1.68 & 1.65 & 61 \\
\hline Soi! water eontent $15 \mathrm{em}$ & 16 & 4.19 & 0.82 & 0.91 & 0.00 & 1.08 & -0.18 & 2,41 & 61 \\
\hline $\begin{array}{l}\text { Hydraulie Conduetivity } \\
50 \mathrm{em}(\operatorname{logs})\end{array}$ & 12 & -3.91 & 0.53 & 0.73 & -0.01 & 1.24 & -0.51 & 1.12 & 51 \\
\hline Soi! water eontent $50 \mathrm{em}$ & 12 & 17.93 & 0.55 & 0.76 & 0.00 & 1.12 & -0.57 & 4.67 & 51 \\
\hline
\end{tabular}

field with low water content values for $15 \mathrm{em}$ depth falls exactly in the region of higher topographic heights (Fig. 4.1b). It is amazing to see that this same region had also low soil water content for the $50 \mathrm{em}$ depth. The maps for hydraulic conductivity and water content for $15 \mathrm{em}$ depth illustrate the reason why their semivariograms are so different when they are scaled which simply is that they represent a very distinct variability. On the other hand, the maps for hydraulic conductivity and soil water content for $50 \mathrm{em}$ depth have variability almost exactly the reverse, with low values of conductivity where the soil water content is high. That was exactly the idea reported by Vieira et al. (1997) that if the semivariograms scale well it is an indication that the two variables either vary almost equally or almost opposite to each other.

The scaled semivariograms for rate of change in soil water content shown in Fig. 4.6 indicate that the variability for water loss is not stable in time. Similar results, were found by Grego et al. (2006) showing that the scaled semivariograms for soil water content may be used to indicate time stability ofthe spatial variability. Five out of twenty nine semivariograms showed pure nugget effect.. AlI the nuggets happened after a large previous rain. Twenty three models were spherical and one was exponential. .

The in Fig. 4.7 show that the rate of change of water content does not repeat in time. It should be noticed that these rate of change in water content are for the three years period which means that there might be climate variability involved in these numbers. The intervals at the beginning of the year' (April, May) probably reftect the amount of snow cover.. Beginning of May 1988 and beginning of April 1989 seem to agree with each other probably of snow melt.. The two rates for 1988 (05/30-06/06 and 06/06-13/06) do not seem to have anything in common and rather are completely the opposite. Beginning of September 1987 seem to agree with end of April 1989 but are not related to topography and/or surface texture but rather with the hydraulic conductivity at 50 em depth. Buttafuoco et al. (2005) showed a high temporal correlation between the soil water contents measured at different times, declining as the interval between the observations increases. The autumn rain events on dry soil produced an erratic distribution pattem of water in the soil and the kriged maps of soil water revealed the dynamics of soil water redistribution owing to evapotranspiration or rainfall, 

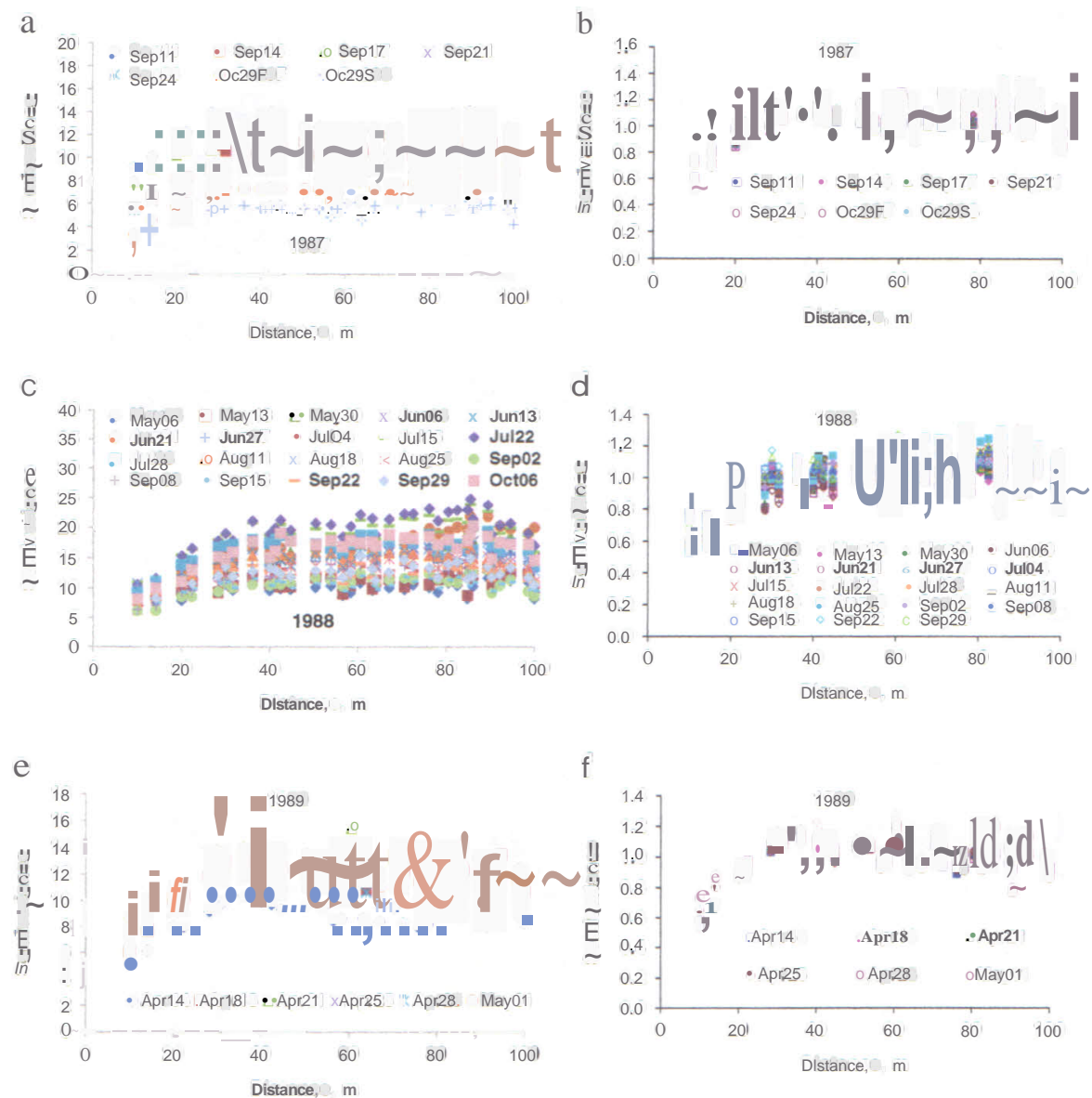

Fig.4.8 Non scaled and scaled semivariograms for soil water content for the 3 years: 1987 (a, b); 1988 (c, d); 1989 (e, f)

\subsubsection{Soil 'memory'}

The follo

The length of time that soil water content expresses correlation with soil water content at an initial time is what may be called as soil 'memory'. The reason for this is in the question 'how long does the soil "remember" the initjal soil water content? In order to illustrate this idea with these three year data, the correlation between water content at some initial time and subsequent soil water content was calculated and plotted in the graphs in Fig. 4.9. For compasison purposes, these calculations were done for both the original values and the residuals of a parabolic trend. The initial times were September/11, May/06 and Apri1/14, respectively for

- Soil st condu

- Tempi hydrau

- Parabc the top

- Rate or times

- Correla

- Unique 
a
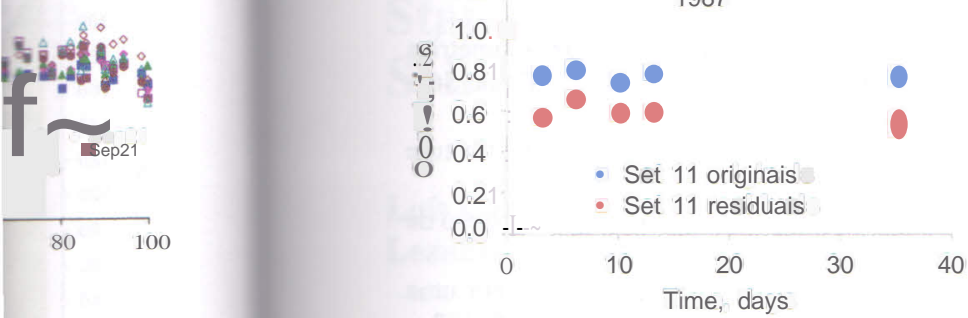

b 1.21988 1.0. c 0.8

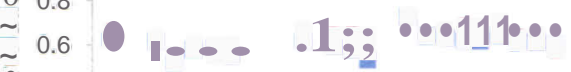
c 0.4

May 06 originais 1 - May 06 residuais

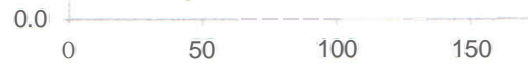
Time, days

$\mathrm{C}$

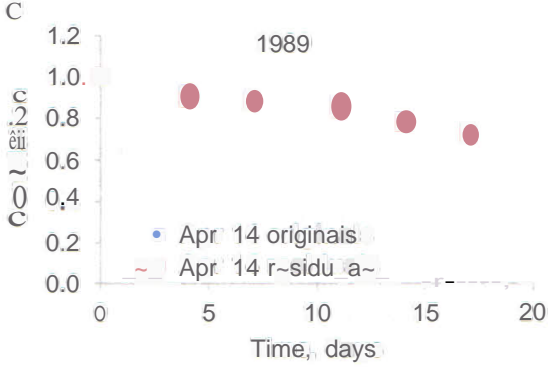

Fig.4.9 Persistence of correlation between soi! water content for the initial sampling date and soil water content in subsequent dates in 1987 (a), 1988 (b) and 1989 (c)

1987, 1988 and 1989. The correlation between any soil water content and the initial one was never lower than 0.6, even for 1988 when the length of time is larger than 150 days. That means that the time stability of the water content is quite high. For 1989, when the data covers only the beginning of the frost free year (April) and the soil is very wet due to snow melt, the correlation remains at approximately 0.8 .

\subsection{Conclusions}

The following conclusions can be extracted in accordance with the text:

$\sim$ Soil structure played a very important role on the spatial distribution of hydraulic conductivity and water content. .

Temporal stability is quite different dusing the year probably because of the hydraulic conductivity role.

- Parabolic trend removal worked well all through the year probably because of the topography.

- Rate of change in water content with time did not repeat variability in different times of the year.

Correlation of water content remains for a Iong time (more than 100 days).

Unique field topography and surface texture may have been the reason for the results. 


\section{References}

Ávila LF, Mello CR, Mello 1M, Silva AM (2011) Padrão espaço-temporal da umidade volumétrica do solo em uma bacia hidrográfica com predominância de Latossolos. Rev Bras Ciênc Solo Viçosa 35:1801-1810

Buttafuoco O, Castrignano A, Busoni E, Dimase AC (2005) Studying the spatial structure evolution of soil water content using multivariate geostatistics. J Hydrol 311:202-218

Oonçalves ACA, Folegatti MV, Silva AP (1999) Estabilidade temporal da distribuição espacial da umidade do solo em área irrigada por pivô central. Rev Bras Ciênc Solo 23:55-164

Orego CR, Vieira SR (2005) Variabilidade espacial de propriedades físicas do solo em uma parcela experimentall Revista Brasileira de Ciência do Solo (Impresso). Viçosa 29:169-177.

Grego CR, Vieira SR, Antonio AM, Della Rosa SC (2006) Oeostatistical analysis for soil water content under no tillage cropping system. Sei Agric 63:341-350

Journel AO, Huijbregts CJ (1978) Mining geostatistics. Academic, San Diego, 600 p

Kachanoski RO, De Jong E (1988) Scale dependence and the temporal persistence of spatial pattems of soil water storage. Water Resour Res 24:85-91

Matheron O (1963) Principles of geostatistics. Econ Oeol (Lancaster) 58:1246-4266

Mcbratney AB, Webster R (1986) Choosing functions for semivariograms of soil properties and fitting them to sampling estimates. J Soil Sei 37:617--\{ij39

NieIsen DR, Tillotson PM, Vieira SR (1983) Analysing field - Measured soi! water properties agricultural. Water Manage 6:63-109

Reynolds WD, Elrick DE (1986) A method for simultaneous in situ measurements in the vadose one of field saturated hydraulic conductivity, sorptivity, and the conductivity-pressure head relationship. Ground Water Monit Rev 6:84-95

Reynolds WD, Vieira SR, Topp OC (1992) An assessment of the single-head analysis for the constant head well permeameter.. Can J Soil Sei (Ottawa) 72:489-501

Topp OC, Davis JL (1985) Measurement of soil water content using time domain refiectometry. (TDR): a field evaluation. Soil Sei Soe Am J 49:574-582

Vauchaud O, De Silane P, Balabanis A, Vauclin M (1985) Temporal stability of spatially measured soil water probability density function. Soil Sei Soe Am J 49:822-827

Vieira SR (2000) Uso de geoestatÍstica em estudos de variabilidade espacial de propriedades do solo. In: Novais RF (ed) Tópicos em Ciência do Solo. Sociedade Brasileira de Ciência do Solo, Viçosa, pp 3-87

Vieira SR, Hatfield JL, Nielsen DR, Biggar JW (1983) Oeoestatistical theory and applieation to variability of some agronomical properties. Hilgardia 51(3):1-75

Vieira SR, Reynolds WD, Topp GC (1988) Spatial variability of hydraulie properties in a highly struetured clay soil. In: Validation of fiow and transport models for the unsaturated zone Ruidoso. Conference Proceedings Ruidoso, Novo Mexico: Departrnent of Agronomy and Horticulture, New Mexico State University, pp 471-483.

Vieira SR, Lombardi Neto F, Burrows IT (1991) Mapeamento da chuva máxima provável para o Estado de São Paulo. Rev Bras Ciênc Solo 15:93-98

Vieira SR, Nielsen DR, Biggar JW, TilJotson PM (1997) The scaling of semivariograms and the kriging estimation. Rev Bras Ciênc Solo 21:525-533

Vieira SR, Orego CR, Toop OC (2008) Analyzing spatial and temporal variability of soil water contento Bragantia 67:463-469

Vieira SR, Carvalho IRP, Ceddia MB, Paz Oonzález A (20IOa) Detrending non stationary data for geostatistical applications. Bragantia 69(Suplemento): 1-8

Vieira SR, Carvalho JRP, Paz Oonzález A (20IOb) Jack knifing for semivasiogram validation. Bragantia 69(Suplemento):97-105 


\section{Progress in Soil Science}

Series Editors: Alfred Hartemink · Alex B. McBratney

Wenceslau Geraldes Teixeira · Marcos Bacis Ceddia · Marta Vasconcelos Ottoni · Guilheme Kangussu Donnagema Editors

\section{Application of Soil Physics in Environmental Analyses}

Measuring, Modelling and Data Integration

The importance to preserve soil and water is widely recognized. Soil physics has grown considerably in the last years, however, those advances are thoroughly dispersed. In this volume, the authors will bring together the effectiveness of new field and lab sensors and the state-of-the-art in modeling and data analysis. The topics have been divided as follows: Part 1 - Integrating data in soil physics proposes re-establishing the knowledge chain, linking tacit knowledge to cutting edge science. The use of field soil data or what has been called hydropedology, is discussed and exemplified. Part 2 - Data analysis in soil physics and pedotransfers functions presents the analysis of data in state-space and geostatistical approaches. Part 3 - Different approaches to characterize soil physical quality indicators is focused on new techniques used to characterize, map and interpret soil physical parameters. The challenge of assessing soil physical quality is discussed from the simplest to the most complex indicators. Part 4 - Sensors and monitoring in soil physics centers the discussion on equipment and sampling techniques for monitoring soil physical parameters. Technological advances are addressed, such as $\mathrm{X}$-ray tomography, which provides a means to evaluate pore topological properties in a noninvasive way. A comparison with in situ and remotely sensed data of soil moisture and limitations in using these data for hydrological modeling are also discussed. Part 5 Creating data bases and models applied to soil physics discusses alternative approaches for modeling water flow and solute transport in the vadose zone. A review of multicomponent solute transport models and examples of their use in agricultural and environmental applications are given. The phenomenon of dynamic non-equilibrium in soil water flow is discussed as the need of a paradigm change. Root water uptake is also covered with advanced approaches and the last two chapters address the challenges to develop soil data bases.

\section{Life Sciences}

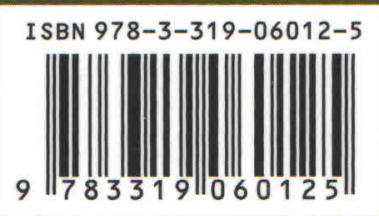

springer.com 